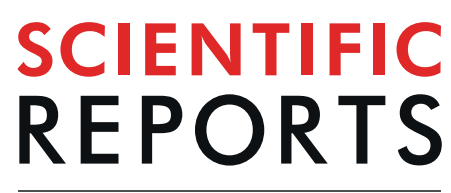

natureresearch

Check for updates

\title{
Trends and causes of mortality in a population-based cohort of HIV-infected adults in Spain: comparison with the general population
}

Carmen Fontela ${ }^{1}$, Aitziber Aguinaga ${ }^{2}$, Conchi Moreno-Iribas ${ }^{3,4}$, Jesús Repáraz ${ }^{5}$, María Rivero ${ }^{5}$, María Gracia ${ }^{5}$, Yugo Floristán ${ }^{3,6}$, Ujué Fresán ${ }^{3,6}$, Ramón San Miguel ${ }^{1}$, Carmen Ezpeleta ${ }^{2}$ \& Jesús Castilla ${ }^{3,6 \bowtie}$

Combination antiretroviral therapy reduces mortality of HIV-infected persons. In Spain, where this therapy is widely available, we aim to evaluate mortality trends and causes of death in HIV-infected adults, and to estimate the excess mortality compared to the general population. From 1999 to 2018 mortality by causes was analyzed in a population-based cohort of adults aged 25 to 74 years diagnosed with HIV infection in Spain. Observed deaths and expected deaths according mortality in the general population of the same sex and age were compared using standardized mortality ratios (SMRs). HIVinfected people increased from 839 in 1999-2003 to 1059 in 2014-2018, median age increased from 37 to 47 years, the annual mortality rate decreased from 33.5 to 20.7 per 1000 person-years and the proportion of HIV-related deaths declined from $64 \%$ to $35 \%$. HIV-related mortality declined from 21.4 to $7.3(p<0.001)$, while non-HIV-related mortality remained stable: 12.1 and 13.4 per 1000 , respectively. Mortality decreased principally in persons diagnosed with AIDS-defining events. In the last decade, 20092018, mortality was still 8.1 times higher among HIV-infected people than in the general population, and even after excluding HIV-related deaths, remained 4.8 times higher. Excess mortality was observed in non-AIDS cancer $(S M R=3.7)$, cardiovascular disease $(S M R=4.2)$, respiratory diseases $(S M R=7.9)$, liver diseases $(S M R=8.8)$, drug abuse $(S M R=47)$, suicide $(S M R=5.3)$ and other external causes $(S M R=6)$. In conclusion, HIV-related mortality continued to decline, while non-HIV-related mortality remained stable. HIV-infected people maintained important excess mortality. Prevention of HIV infections in the population and promotion of healthy life styles in HIV-infected people must be a priority.

Since the introduction of combined antiretroviral therapies in the second half of the 1990s, morbidity and mortality in HIV-infected persons have decreased steeply ${ }^{1-3}$, and their life expectancy has improved ${ }^{3-5}$. HIV-infected persons may die of HIV-related and non-HIV-related causes. The first ones mark the difference with the general population, but may be averted by early and successful antiretroviral therapy ${ }^{3}$. HIV-related mortality has been associated with the long length of infection, higher age at seroconversion, late HIV diagnosis, incomplete adherence to antiretroviral therapies and use of suboptimal regimens ${ }^{1,2,6,7}$. Risk behaviours related to HIV transmission may have other negative effects in health as drug abuse problems and other sexually or blood transmitted infections as hepatitis B or C that could increase non-HIV-related mortality ${ }^{8-12}$.

Clinical cohorts of HIV-infected patients have described important reduction in mortality ${ }^{8-12}$, but they may not be representative of the overall mortality in the HIV-infected population, because HIV-infections diagnosed

${ }^{1}$ Department of Pharmacy, Complejo Hospitalario de Navarra - IdiSNA, Pamplona, Spain. ${ }^{2}$ Department of Clinical Microbiology, Complejo Hospitalario de Navarra- IdiSNA, Pamplona, Spain. Instituto de Salud Pública de Navarra - IdiSNA, Pamplona, Spain. ' Red de Investigación en Servicios de Salud en Enfermedades Crónicas (REDISSEC), Pamplona, Spain. ${ }^{5}$ Infectious Diseases Unit, Complejo Hospitalario de Navarra - IdiSNA, Pamplona, Spain. ${ }^{6} \mathrm{CIBER}$ Epidemiología y Salud Pública (CIBERESP), Pamplona, Spain. ${ }^{\circledR e}$-mail: jcastilc@navarra.es 


\begin{tabular}{|c|c|c|c|c|}
\hline & 1999-2003 & $2004-2008$ & 2009-2013 & 2014-2018 \\
\hline HIV-infected persons in follow-up, $\mathrm{n}$ & 839 & 881 & 964 & 1059 \\
\hline \multicolumn{5}{|l|}{ Sex, n (\%) } \\
\hline Male & $568(67.7)$ & $584(66.3)$ & $637(66.1)$ & $709(66.9)$ \\
\hline Female & $271(32.3)$ & $297(33.7)$ & $327(33.9)$ & $350(33.1)$ \\
\hline \multicolumn{5}{|l|}{ Transmission category, $\mathrm{n}(\%)$} \\
\hline Injecting drug use & $597(71.2)$ & $550(62.4)$ & $499(51.8)$ & $456(43.1)$ \\
\hline Men who had sex with men & $53(6.3)$ & $80(9.1)$ & $133(13.8)$ & $212(20.0)$ \\
\hline Heterosexual transmission & $166(19.8)$ & $220(25.0)$ & $285(29.6)$ & $340(32.1)$ \\
\hline Other risk or unknown & $23(2.7)$ & $31(3.5)$ & $47(4.9)$ & $51(4.8)$ \\
\hline Age, years, median [interquartil range] ${ }^{\mathrm{a}}$ & $37[34-41]$ & $41[37-44]$ & $43[39-47]$ & $47[40-52]$ \\
\hline $\begin{array}{l}\text { Time since HIV diagnosis, median in } \\
\text { years [interquartil range] }^{\mathrm{a}}\end{array}$ & $9[4-12]$ & $11[6-15]$ & $13[4-18]$ & $14[4-22]$ \\
\hline $\begin{array}{l}\text { Year of HIV diagnosis, median } \\
\text { [interquartil range] }\end{array}$ & $\begin{array}{l}1992 \\
{[1988-1996]}\end{array}$ & $\begin{array}{l}1993 \\
{[1990-1999]}\end{array}$ & $\begin{array}{l}1996 \\
{[1991-2004]}\end{array}$ & $\begin{array}{l}1999 \\
{[1992-2010]}\end{array}$ \\
\hline AIDS-defining event diagnosis, $\mathrm{n}(\%)$ & $296(35.3)$ & $307(34.8)$ & $291(30.2)$ & $286(27.0)$ \\
\hline Anti-HCV positive, $\mathrm{n}(\%)$ & $322(38.4)$ & $368(41.8)$ & $383(39.7)$ & $405(38.2)$ \\
\hline HCV-RNA positive ever, n (\%) & $251(29.9)$ & $264(29.9)$ & $268(27.8)$ & $270(25.4)$ \\
\hline Born out of Spain, $n(\%)$ & $30(3.6)$ & $84(9.5)$ & $145(15.0)$ & $207(19.5)$ \\
\hline Antiretroviral treatment, n (\%) & $605(72.1)$ & $660(74.9)$ & $745(77.3)$ & $931(87.9)$ \\
\hline Person-years of follow-up & 3555 & 3826 & 4172 & 4693 \\
\hline Deaths, n (\%) & $119(14.2)$ & $101(11.5)$ & $89(9.2)$ & $97(9.2)$ \\
\hline Mortality rate per 1000 person-years & 33.5 & 26.4 & 21.3 & 20.7 \\
\hline
\end{tabular}

Table 1. Characteristics of the cohort of people diagnosed with HIV infection by study period. ${ }^{\mathrm{a} D a t a}$ referred to the middle of the period. HCV: hepatitis C virus.

before the combined antiretroviral therapy availability, patients deceased before starting of clinical follow-up, those who refuse treatments or who do not contact the healthcare system are usually excluded.

In the first years with availability of effective antiretroviral therapies, a considerable excess mortality was still reported in HIV-infected persons ${ }^{13}$. Since then, relevant clinical advances has been introduced: the initiation of treatment turned from a threshold of CD4 count to as soon as possible after diagnosis ${ }^{6,14,15}$, the progressive introduction of safer antiretroviral combinations ${ }^{16}$, and direct acting antiviral regimens for hepatitis $\mathrm{C}$ virus (HCV) co-infected patients ${ }^{17}$. All these interventions are expected to further reduce the excess mortality in people living with HIV-infection. Therefore, we aimed to describe recent changes in mortality and causes of death in a population-based cohort of persons diagnosed with HIV infection, and to compare with mortality in the general population of the same age and sex and living in the same region.

\section{Results}

Characteristics of the cohort. From 1999-2003 to 2014-2018 the number of prevalent cases diagnosed with HIV infection increased from 839 to 1059. The proportion of women remained around one third. HIV infections related to injecting drug use decreased from $71.2 \%$ to $43.1 \%$, and those in men who had sex with men increased from $6.3 \%$ to $20.0 \%$. The median age increased from 37 to 47 years, and the time since the diagnosis of HIV from 9 to 14 years. The proportion of people born out of Spain increased from $3.6 \%$ to $19.5 \%$, and patients who have started antiviral therapy increased from $72.1 \%$ to $87.9 \%$. The percentage of HCV-RNA positive patients declined from $29.9 \%$ to $25.4 \%$, and most of them (93.7\%) had history of injecting drug use. HIV-infected people in follow-up who had been diagnosed with AIDS decreased from $35.3 \%$ to $27.0 \%$ (Table 1 ).

Trends in mortality. All-cause crude mortality fell by $38 \%$ from 33.5 in $1999-2003$ to 20.7 per 1000 person-years (PY) in 2014-2018. Crude mortality declined by $3 \%$ annually and mortality adjusted for sex, age, foreign-born and transmission category declined by $5 \%$ (adjusted rate ratio $[\mathrm{aRR}]=0.95 ; \mathrm{p}<0.001$ ). In 19992003, mortality rate was higher in males than females (38.8 vs 22.9 per 1000 PY; $p=0.013$ ); however, the more pronounced decline in mortality in males $(\mathrm{aRR}=0.95, \mathrm{p}<0.001)$ than in females $(\mathrm{aRR}=0.98, \mathrm{p}=0.323)$ resulted in similar mortality rates in 2014-2018 (21.0 and 20.1 per 1000 PY, respectively; $\mathrm{p}=0.859$ ). Declines in adjusted mortality rates were similar regardless the age group, history of injecting drug use or the foreign-born. All-cause mortality decreased regardless if HIV diagnosis had been before or in or after $1997(\mathrm{aRR}=0.95, \mathrm{p}=0.0068$ and $\mathrm{aRR}=0.96, \mathrm{p}=0.013$, respectively) (Table 2 ).

HIV-related deaths were responsible for $64 \%$ of the total mortality in the cohort in 1999-2003 and decreased to $35 \%$ in 2014-2018. HIV-related crude mortality decreased 66\%, from 21.4 to 7.2 per 1000 PY, and the adjusted rate decreased $8 \%$ annually $(a R R=0.92 ; p<0.001)$. Crude mortality from other causes increased slightly, from 12.1 to 13.5 per $1000 \mathrm{PY}$, but no statistically significant trend was detected in the crude or adjusted analysis $(\mathrm{aRR}=1.00 ; \mathrm{p}=0.913)$. Mortality due to drug addiction or overdose decreased from 4.2 to 0.9 per $1000 \mathrm{PY}$, that supposes an unadjusted annual decline of $11 \%$ (unadjusted $R R=0.89 ; p=0.001$ ), but this trend partially 


\begin{tabular}{|c|c|c|c|c|c|c|c|c|c|c|c|c|}
\hline & \multicolumn{2}{|c|}{ 1999-2003 } & \multicolumn{2}{|c|}{ 2004-2008 } & \multicolumn{2}{|c|}{ 2009-2013 } & \multicolumn{2}{|c|}{ 2014-2018 } & \multicolumn{2}{|c|}{ Unadjusted trend $^{\mathrm{a}}$} & \multicolumn{2}{|c|}{ Adjusted trend $^{\mathrm{a}}$} \\
\hline & $\mathbf{N}$ & Rate & $\mathbf{N}$ & Rate & $\mathbf{N}$ & Rate & $\mathbf{N}$ & Rate & $\mathbf{R R}$ & p-value & aRR & p-value \\
\hline \multicolumn{13}{|l|}{ Sex } \\
\hline Male & 92 & 38.8 & 77 & 30.7 & 64 & 23.8 & 65 & 21.0 & 0.96 & $<0.001$ & 0.95 & $<0.001$ \\
\hline Female & 27 & 22.9 & 24 & 18.3 & 25 & 16.8 & 32 & 20.1 & 0.99 & 0.627 & 0.98 & 0.326 \\
\hline \multicolumn{13}{|l|}{ Age, years } \\
\hline$<45$ years & 93 & 29.2 & 70 & 23.5 & 41 & 17.6 & 20 & 11.9 & 0.95 & $<0.001$ & 0.96 & 0.016 \\
\hline$\geq 45$ years & 26 & 71.0 & 31 & 36.8 & 48 & 26.1 & 77 & 25.6 & 0.94 & $<0001$ & 0.94 & $<0.001$ \\
\hline \multicolumn{13}{|c|}{ History of injecting drug use } \\
\hline Yes & 90 & 33.8 & 74 & 29.7 & 57 & 24.9 & 58 & 27.5 & 0.98 & 0.115 & 0.96 & 0.004 \\
\hline No & 29 & 32.6 & 27 & 20.3 & 32 & 17.0 & 39 & 15.1 & 0.95 & 0.003 & 0.95 & 0.002 \\
\hline \multicolumn{13}{|c|}{ Country of birth } \\
\hline Spain & 117 & 33.7 & 98 & 27.7 & 84 & 23.4 & 87 & 22.9 & 0.97 & 0.003 & 0.95 & $<0.001$ \\
\hline Other & 2 & 24.4 & 3 & 10.4 & 5 & 8.6 & 10 & 11.1 & 0.98 & 0.636 & 0.96 & 0.445 \\
\hline \multicolumn{13}{|c|}{ Year of HIV diagnosis } \\
\hline Before 1997 & 96 & 32.7 & 80 & 30.2 & 62 & 26.3 & 56 & 26.7 & 0.95 & 0.006 & 0.95 & 0.007 \\
\hline 1997 or after & 23 & 37.1 & 21 & 17.9 & 27 & 14.9 & 41 & 15.8 & 0.98 & 0.142 & 0.96 & 0.001 \\
\hline Total & 119 & 33.5 & 101 & 26.4 & 89 & 21.4 & 97 & 20.7 & 0.97 & $<0.001$ & 0.95 & $<0.001$ \\
\hline
\end{tabular}

Table 2. Number of deaths, annual average crude mortality rate per 1000 person-years, and crude and adjusted annual mortality trend in the cohort of people diagnosed with HIV infection. ${ }^{a}$ Average annual trend unadjusted and adjusted for sex, age group (25-34; 35-44, 45-54, 55-64, 65-74), country of birth (Spain or other) and transmission category (history of injecting drug use, men who had sex with men, heterosexual risk exposure, and other risk or unknown). RR, rate ratio of trend for annual change in mortality.

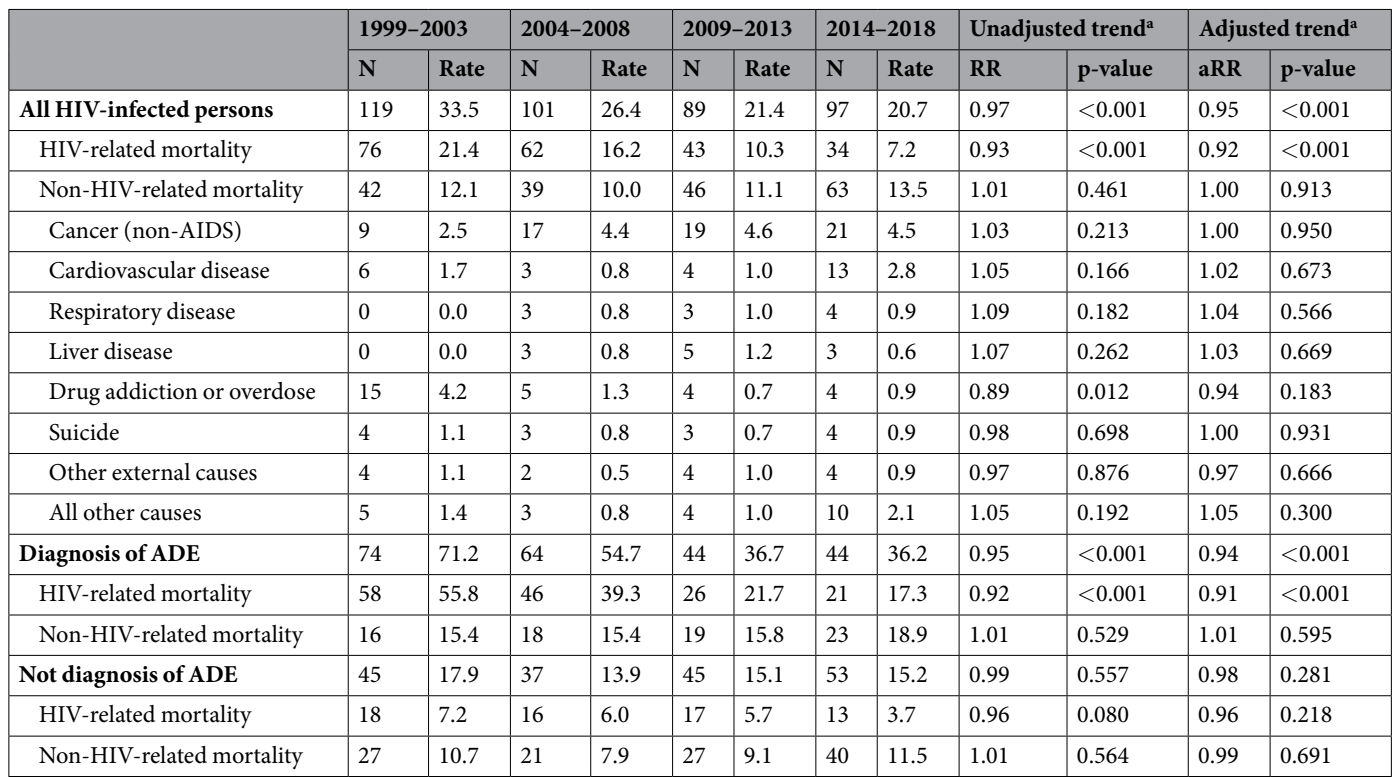

Table 3. Number of deaths, annual average crude mortality rate per 1000 person-years, and crude and adjusted annual mortality trend in the cohort of people diagnosed with HIV infection. a Average annual trend unadjusted and adjusted for sex, age group (25-34; 35-44, 45-54, 55-64, 65-74), country of birth (Spain or other) and transmission category (history of injecting drug use, men who had sex with men, heterosexual risk exposure, and other risk or unknown). RR, rate ratio of trend for annual change in mortality. ADE, AIDS-defining events.

disappeared in the adjusted analysis $(\mathrm{aRR}=0.94 ; \mathrm{p}=0.183)$. No statistically significant change was observed in any of the other specific non-HIV-related causes of death (Table 3).

In patients who had had diagnosis of AIDS-defining events mortality decreased from 71.2 to 36.2 per $1000 \mathrm{PY}$ $(\mathrm{aRR}=0.94 ; \mathrm{p}<0.001)$, but in people never diagnosed with AIDS-defining events the decline was minor and not statistically significant, from 17.9 to $15.2(\mathrm{aRR}=0.98 ; \mathrm{p}=0.281)$ (Table 3$)$.

Comparison with mortality in the general population. In the 1999-2003 period, all-cause mortality in people diagnosed with HIV infection was 20.4 (95\% confidence interval [CI]: 17.0-24.3) times higher than in 
the general population of the same sex and age group, and in 2014-2018 it was still 7.4 (95\% CI: 6.0-9.0) times higher. After excluding HIV-related deaths, mortality in HIV-infected people declined from 7.2 to 4.8 times higher than that of the general population in the same periods (Table 4). For all groups of HIV-infected patients analysed, mortality was statistically significant higher than expected from the general population, but in general, these differences declined over time. Standard mortality ratios (SMRs) were higher in females than males, and in people younger than 45 years than in the older ones; however the excess mortality rates were in general higher in males and in the older age group. Although the lowest SMRs were observed in HIV-infected men who had sex with men, in the period 2014-2018 their mortality was still 4.3 times higher than in male general population. Excess mortality rates and SMRs were higher in persons diagnosed with HIV before 1997 than in those diagnosed in or after, but in both cases declined over time. Nevertheless, in the period 2014-2018, mortality in persons diagnosed with HIV infection in 1997 or after still was 6.1 higher than in general population (Table 4).

In the 2009-2018 decade, mortality in HIV-infected population was statistically significant higher than the expected for all non-HIV-related causes of death considered. The most pronounced SMRs were observed in drug addiction or overdose (46.7 times higher), liver disease ( 8.8 times higher) and respiratory disease (7.9 times higher); however, in absolute terms, the highest excess mortality rates were observed in non-AIDS cancer (3.3 deaths per $1000 \mathrm{PY}$ ) and cardiovascular disease (1.5 per $1000 \mathrm{PY})$. Excess mortality rates were quite similar in males (19.0 per $1000 \mathrm{PY}$ ) and females (17.4 per $1000 \mathrm{PY}$ ); however, this resulted in a higher SMR for females (16.1) than for males (6.7). Excess mortality was more pronounced in HIV-infected persons with history of injecting drug use. In this group, all-cause mortality was 11 times higher and non-HIV related mortality was 6.9 times higher than in the general population, while they were 5.7 and 3.1 times higher, respectively, among people without history of injecting drug use (Table 5).

\section{Discussion}

From 1999 to 2018, the adjusted mortality rate in a population-based cohort of people with a diagnosis of HIV infection declined by $5 \%$ annually, following the trend that had begun with the introduction of highly active antiretroviral therapies ${ }^{3,10}$. This trend has contributed to reduce the excess mortality in the HIV-infected population. Nevertheless, in the 2014-2018 period, mortality still was 7.4 times higher than in the general population of the same sex and age. HIV-infected men who had sex with men showed the lowest excess mortality as compared to male general population, probably due to the earlier diagnoses and lower probability of other risk factors and comorbidities than in other transmission categories; however their mortality was still 4.3 times higher than expected in the last period. Although persons diagnosed with HIV infection in 1997 or after, period of use of combined antiretroviral therapy, had lower mortality than those diagnosed before, they still had 6.1 times higher mortality than the general population. These findings suggest that one part of the excess mortality associated to HIV-infection may be very difficult to control even with wide availability of antiretroviral treatments, and that promotion of healthy lifestyles in these patients is also very important. These findings also highlight the great advantage in terms of life expectancy that primary prevention of HIV transmission still has over the antiretroviral treatment.

The excess mortality observed in the current study was greater than that reported from clinical cohorts of HIV-infected patients, which may be explained by selection of patients in this kind of cohorts ${ }^{8-12}$; however, our results are close to those of another population-based study ${ }^{18-20}$.

HIV-related mortality decreased from 2 to 1 out of 3 deaths during the study period. The HIV-related mortality rate declined $8 \%$ annually, being the main component of the reduction in excess overall mortality among HIV-infected population. Although highly active antiretroviral therapy was already available before the study period, since then safer antiretroviral drug combinations that favour adherence have been progressively introduced $^{16}$, and initiation of these treatments turned from a threshold based on CD4 count to as soon as possible after diagnosis may have contributed to maintain the reduction in HIV-related mortality ${ }^{6,14,15}$. The main reduction in mortality was observed in patients with diagnosis of AIDS-defining events, in whom the risk of mortality ${ }^{21}$ and the potential benefit by a successful antiretroviral therapy are higher. However, mortality reduction was small or null in HIV-infected persons without prior AIDS-defining events, since mortality among them is mainly related to other comorbidities and risk factors, and its prevention requires other kind of preventive and healthcare interventions.

Non-HIV-related mortality remained stable during the study period, with an important excess as compared to the general population. Excess mortality in relative terms (SMR) was more pronounced in drug addiction or overdose and liver disease, since these causes were strongly associated to history of injecting drug use, which was present in many of HIV-infected people ${ }^{11,13}$. Nevertheless, the highest excess mortality rates were observed in cancer and cardiovascular disease, since they were also leader causes of death in HIV-infected population as they are in the general population. This finding could be explained by the higher frequency of tobacco, alcohol and recreational drug consumption, the faster aging and the premature presentation of comorbidities in HIV-infected people ${ }^{22}$.

History of injecting drug use was associated to higher mortality by most causes. It was present in the majority of deaths by drug overdoses or addiction, was a risk factor for coinfections by hepatitis B and C viruses and was frequently associated to injuries, suicide and to unhealthy life styles as alcohol abuse and smoking ${ }^{23,24}$.

During the study period, excess mortality rates declined more in HIV-infected males than in females, and by the last study period the differences by sexes had disappeared. Females presented higher excess mortality in relative terms, since in the general population women have lower mortality than men. This is partly explained because women assume less risk and take more care of their health, which may not be true in HIV-infected females, who have been associated with situations of disadvantage for the care of their health ${ }^{24-26}$.

Since excess mortality rates were higher in people older than 45 years, the aging of the cohort and the premature presentation of comorbidities ${ }^{22}$ favor to maintain the excess mortality. However the higher SMRs in people under 45 years of age indicate the important relative impact of HIV infection on mortality since young ages.

In the studied cohort, people with history of injecting drug use predominated, although there was a progressive increase in the proportion of people probably infected by sexual transmission, coinciding with the 


\begin{tabular}{|c|c|c|c|c|}
\hline $\begin{array}{l}\text { Population group } \\
\text { and period }\end{array}$ & $\begin{array}{l}\text { Number } \\
\text { of deaths }\end{array}$ & $\begin{array}{l}\text { Mortality rate per } \\
1000 \mathrm{PY}\end{array}$ & $\begin{array}{l}\text { Excess mortality rate } \\
\text { per } 1000 \mathrm{PY}(95 \% \mathrm{CI})^{\mathrm{a}}\end{array}$ & $\begin{array}{l}\text { Standardized mortality } \\
\text { ratio }(95 \% \mathrm{CI})^{\mathrm{a}}\end{array}$ \\
\hline \multicolumn{5}{|l|}{ All-cause deaths } \\
\hline 1999-2003 & 119 & 33.5 & $31.8(26.4-37.9)$ & $20.4(17.0-24.3)$ \\
\hline 2004-2008 & 101 & 26.4 & $24.6(20.1-29.5)$ & $14.2(11.7-17.2)$ \\
\hline 2009-2013 & 89 & 21.4 & $19.0(15.4-23.4)$ & $9.1(7.3-11.1)$ \\
\hline 2014-2018 & 97 & 20.7 & $17.9(14.5-21.7)$ & $7.4(6.0-9.0)$ \\
\hline \multicolumn{5}{|c|}{ Non-HIV-related deaths } \\
\hline 1999-2003 & 42 & 11.8 & $10.2(7.6-13.7)$ & $7.2(5.3-9.7)$ \\
\hline 2004-2008 & 39 & 10.0 & $8.4(5.9-11.2)$ & $5.5(4.0-7.4)$ \\
\hline 2009-2013 & 46 & 11.1 & $8.7(6.5-11.7)$ & $4.7(3.5-6.2)$ \\
\hline 2014-2018 & 63 & 13.4 & $10.6(8.1-13.6)$ & $4.8(3.7-6.1)$ \\
\hline \multicolumn{5}{|l|}{ Male } \\
\hline 1999-2003 & 92 & 38.8 & $36.6(29.8-44.3)$ & $18.3(14.8-22.3)$ \\
\hline 2004-2008 & 77 & 30.7 & $28.4(22.8-35.3)$ & $13.0(10.4-16.2)$ \\
\hline 2009-2013 & 64 & 23.9 & $20.8(16.1-26.3)$ & $7.7(5.9-9.7)$ \\
\hline $2014-2018$ & 65 & 21.0 & $17.4(1.34-22.0)$ & $5.9(4.6-7.5)$ \\
\hline \multicolumn{5}{|l|}{ Female } \\
\hline 1999-2003 & 27 & 22.8 & $22.2(15.9-31.1)$ & $33.2(22.5-47.5)$ \\
\hline 2004-2008 & 24 & 18.3 & $17.4(11.7-24.4)$ & $20.2(13.2-29.6)$ \\
\hline 2009-2013 & 25 & 16.8 & $15.8(10.9-22.4)$ & $17.2(11.4-25.1)$ \\
\hline 2014-2018 & 32 & 20.1 & $18.8(13.2-25.4)$ & $15.1(10.5-21.1)$ \\
\hline \multicolumn{5}{|l|}{ Aged $<45$ years } \\
\hline 1999-2003 & 93 & 29.2 & $28.0(23.0-34.0)$ & $24.8(20.1-30.2)$ \\
\hline 2004-2008 & 70 & 23.5 & $22.4(17.7-27.8)$ & $22.1(17.4-27.8)$ \\
\hline 2009-2013 & 41 & 17.6 & $16.7(12.6-22.3)$ & $20.9(15.2-28.1)$ \\
\hline 2014-2018 & 20 & 11.9 & $11.2(7.3-16.2)$ & $18.1(11.4-27.4)$ \\
\hline \multicolumn{5}{|l|}{ Aged $\geq 45$ years } \\
\hline 1999-2003 & 26 & 71.0 & $65.3(32.8-91.3)$ & $12.4(8.3-18.0)$ \\
\hline 2004-2008 & 31 & 37.0 & $32.3(23.2-45.5)$ & $7.9(5.5-11.1)$ \\
\hline 2009-2013 & 48 & 26.2 & $21.9(16.5-29.1)$ & $6.1(4.6-8.0)$ \\
\hline 2014-2018 & 77 & 25.6 & $21.6(17.0-26.8)$ & $6.4(5.1-7.9)$ \\
\hline \multicolumn{5}{|c|}{ History of injecting dug use $\mathrm{e}^{\mathrm{b}}$} \\
\hline 1999-2003 & 89 & 33.4 & $32.0(26.1-39.0)$ & $25.2(20.4-30.9)$ \\
\hline 2004-2008 & 74 & 29.6 & $28.1(22.6-35.0)$ & $19.9(15.8-24.9)$ \\
\hline 2009-2013 & 57 & 24.8 & $22.7(17.7-29.2)$ & $11.7(8.9-15.0)$ \\
\hline 2014-2018 & 58 & 27.4 & $24.6(19.2-31.7)$ & $9.9(7.6-12.7)$ \\
\hline \multicolumn{5}{|c|}{ Men who had sex with men ${ }^{c}$} \\
\hline 1999-2003 & 3 & 14.9 & $12.1(5.4-27.6)$ & $5.4(1.4-14.6)$ \\
\hline 2004-2008 & 7 & 22.1 & $19.4(10.9-36.8)$ & $8.2(3.6-16.3)$ \\
\hline 2009-2013 & 5 & 10.1 & $7.4(3.3-14.6)$ & $3.7(1.4-8.3)$ \\
\hline $2014-2018$ & 10 & 11.5 & $8.8(4.7-15.0)$ & $4.3(2.2-7.7)$ \\
\hline \multicolumn{5}{|c|}{ Heterosexual risk exposure $^{\mathrm{b}}$} \\
\hline $1999-2003$ & 24 & 40.2 & $37.6(25.8-53.8)$ & $15.2(10.0-22.3)$ \\
\hline 2004-2008 & 19 & 21.5 & $19.0(12.1-28.0)$ & $8.5(5.3-13.0)$ \\
\hline 2009-2013 & 22 & 18.4 & $15.9(10.2-22.8)$ & $7.2(4.6-10.7)$ \\
\hline 2014-2018 & 24 & 16.3 & $13.5(8.3-19.3)$ & $5.8(3.8-8.4)$ \\
\hline \multicolumn{5}{|c|}{ HIV diagnosis before 1997} \\
\hline 1999-2003 & 96 & 32.7 & $31.2(25.6-37.7)$ & $22.0(17.9-26.8)$ \\
\hline 2004-2008 & 80 & 30.2 & $28.4(22.9-35.1)$ & $17.1(13.6-21.1)$ \\
\hline 2009-2013 & 62 & 26.3 & $23.9(18.7-30.4)$ & $10.9(8.4-13.8)$ \\
\hline 2014-2018 & 56 & 26.7 & $23.6(18.1-30.3)$ & $8.6(6.5-11.0)$ \\
\hline \multicolumn{5}{|c|}{ HIV diagnosis in 1997 or after } \\
\hline 1999-2003 & 23 & 37.1 & $34.7(23.5-49.8)$ & $15.3(9.9-22.5)$ \\
\hline 2004-2008 & 21 & 17.9 & $15.8(10.4-23.2)$ & $8.6(5.5-12.9)$ \\
\hline 2009-2013 & 27 & 14.9 & $12.6(8.5-17.7)$ & $6.5(4.4-9.3)$ \\
\hline 2014-2018 & 41 & 15.8 & $13.2(9.7-17.9)$ & $6.1(4.4-8.2)$ \\
\hline
\end{tabular}

Table 4. Comparison of mortality between HIV-infected subjects and the general population of the same sex and age group, by population group and period, 1999-2018. ${ }^{\mathrm{a}}$ Mid-P exact test. ${ }^{\mathrm{b}}$ Expected deaths were calculated from the total reference population. ${ }^{c}$ Expected deaths were calculated from the male reference population. $\mathrm{CI}$, confidence interval; PY, person-years. 


\begin{tabular}{|c|c|c|c|c|}
\hline & $\begin{array}{l}\text { Number of } \\
\text { deaths }\end{array}$ & $\begin{array}{l}\text { Mortality rate per } \\
1000 \mathrm{PY}\end{array}$ & $\begin{array}{l}\text { Excess mortality rate } \\
\text { per } 1000 \mathrm{PY}(95 \% \mathrm{CI})^{\mathrm{a}}\end{array}$ & $\begin{array}{l}\text { Standardized mortality } \\
\text { ratio }(95 \% \mathrm{CI})^{\mathrm{a}}\end{array}$ \\
\hline \multicolumn{5}{|l|}{ All HIV-infected persons } \\
\hline All-cause mortality & 186 & 21.0 & $18.4(15.9-21.4)$ & $8.1(7.0-9.3)$ \\
\hline Non-HIV-related mortality & 109 & 12.3 & $9.7(8.0-11.9)$ & $4.8(3.9-5.7)$ \\
\hline Cancer (non-AIDS) & 40 & 4.5 & $3.3(2.4-4.6)$ & $3.7(2.7-5.0)$ \\
\hline Cardiovascular disease & 17 & 1.9 & $1.5(0.9-2.2)$ & $4.2(2.5-6.5)$ \\
\hline Respiratory disease & 7 & 0.8 & $0.7(0.4-1.3)$ & $7.9(3.4-15.5)$ \\
\hline Liver disease & 8 & 0.9 & $0.8(4.6-14.8)$ & $8.8(4.1-16.6)$ \\
\hline Drug addiction or overdose & 8 & 0.9 & $0.9(0.5-1.5)$ & $46.7(21.7-88.6)$ \\
\hline Suicide & 7 & 0.8 & $0.6(3.2-1.2)$ & $5.3(2.3-10.6)$ \\
\hline Other external causes & 8 & 0.9 & $0.8(0.4-1.3)$ & $6.0(2.8-11.4)$ \\
\hline All other causes & 14 & 1.1 & $1.2(0.7-1.9)$ & $4.0(2.3-6.5)$ \\
\hline \multicolumn{5}{|l|}{ Male } \\
\hline All-cause mortality & 129 & 22.3 & $19.0(15.8-22.6)$ & $6.7(5.6-7.9)$ \\
\hline Non-HIV-related mortality & 78 & 13.5 & $10.2(7.9-12.8)$ & $4.0(3.2-5.0)$ \\
\hline Cancer (non-AIDS) & 27 & 4.7 & $3.2(2.1-4.7)$ & $3.1(2.1-4.5)$ \\
\hline Cardiovascular disease & 12 & 2.1 & $1.4(0.8-2.5)$ & $3.2(1.7-5.4)$ \\
\hline Respiratory disease & 5 & 0.9 & $0.7(3.8-15.2)$ & $6.5(2.4-14.3)$ \\
\hline Liver disease & 7 & 1.2 & $1.1(0.6-2.0)$ & $8.4(3.7-16.7)$ \\
\hline Drug addiction or overdose & 6 & 1.0 & $1.0(0.5-1.8)$ & $38.0(15.4-79.0)$ \\
\hline Suicide & 6 & 1.0 & $0.9(0.4-1.5)$ & $5.7(2.3-11.8)$ \\
\hline Other external causes & 3 & 0.5 & $0.3(0.1-0.6)$ & $2.5(0.6-6.7)$ \\
\hline All other causes & 12 & 1.4 & $1.6(1.0-2.7)$ & $4.1(2.2-6.9)$ \\
\hline \multicolumn{5}{|l|}{ Female } \\
\hline All-cause mortality & 57 & 18.5 & $17.4(12.5-22.2)$ & $16.1(12.3-20.7)$ \\
\hline Non-HIV-related mortality & 31 & 10.0 & $8.9(6.3-12.4)$ & $8.7(6.1-12.3)$ \\
\hline Cancer (non-AIDS) & 13 & 4.2 & $3.5(2.0-5.5)$ & $6.2(3.4-10.3)$ \\
\hline Cardiovascular disease & 5 & 1.6 & $1.5(0.7-2.8)$ & $16.3(6.0-36.2)$ \\
\hline Respiratory disease & 2 & 0.6 & $0.6(0.2-1.2)$ & $17.0(2.9-56.2)$ \\
\hline Liver disease & 1 & 0.3 & $0.3(0.1-15.0)$ & $12.0(0.6-59.1)$ \\
\hline Drug addiction or overdose & 2 & 0.6 & $0.6(0.2-1.2)$ & $147.7(24.8-488)$ \\
\hline Suicide & 1 & 0.3 & $0.2(0.1-7.9)$ & $3.9(0.2-19.2)$ \\
\hline Other external causes & 5 & 1.6 & $1.6(0.7-2.8)$ & $44.5(16.3-98.7)$ \\
\hline All other causes & 2 & 0.6 & $0.5(0.2-1.2)$ & $3.6(0.6-12.0)$ \\
\hline \multicolumn{5}{|l|}{ History of injecting drug use } \\
\hline All-cause mortartality & 117 & 26.6 & $24.2(20.1-28.9)$ & $11.0(9.1-13.1)$ \\
\hline Non-HIV-related mortality & 52 & 16.6 & $14.2(11.2-17.8)$ & $6.9(5.4-8.6)$ \\
\hline Cancer (non-AIDS) & 24 & 5.5 & $4.4(3.0-6.5)$ & $4.9(3.2-7.2)$ \\
\hline Cardiovascular disease & 10 & 2.3 & $1.8(1.1-3.3)$ & $5.3(2.7-9.5)$ \\
\hline Respiratory disease & 3 & 0.7 & $0.6(0.2-1.3)$ & $8.8(2.2-24.0)$ \\
\hline Liver disease & 8 & 1.8 & $1.7(9.4-3.0)$ & $16.8(7.8-31.9)$ \\
\hline Drug addiction or overdose & 7 & 1.6 & $1.6(0.8-2.7)$ & $74.1(32.5-147)$ \\
\hline Suicide & 5 & 1.1 & $1.0(0.5-2.0)$ & $6.8(2.5-15.2)$ \\
\hline Other external causes & 6 & 1.4 & $1.2(0.6-2.3)$ & $9.3(3.8-19.3)$ \\
\hline All other causes & 8 & 1.8 & $1.5(0.8-2.7)$ & $5.0(2.3-9.7)$ \\
\hline \multicolumn{5}{|l|}{ No history of injecting drug use } \\
\hline All-cause mortality & 71 & 15.9 & $13.1(10.3-16.6)$ & $5.7(4.5-7.2)$ \\
\hline Non-HIV-related mortality & 39 & 8.7 & $6.0(4.2-8.3)$ & $3.1(2.3-4.2)$ \\
\hline Cancer (non-AIDS) & 16 & 3.6 & $2.3(1.4-3.8)$ & $2.7(1.6-4.3)$ \\
\hline Cardiovascular disease & 7 & 1.6 & $1.1(0.5-2.0)$ & $3.1(1.4-6.2)$ \\
\hline Respiratory disease & 4 & 0.9 & $0.8(0.4-1.6)$ & $7.2(2.3-17.3)$ \\
\hline Liver disease & 0 & 0 & 0 & - \\
\hline Drug addiction or overdose & 1 & 0.2 & $0.2(0.1-1.2)$ & $12.9(0.6-63.8)$ \\
\hline Suicide & 2 & 0.4 & $0.3(0.1-0.8)$ & $3.4(0.6-11.4)$ \\
\hline Other external causes & 2 & 0.4 & $0.3(0.1-0.8)$ & $2.9(0.5-9.5)$ \\
\hline All other causes & 7 & 1.6 & $1.1(0.6-2.3)$ & $3.6(1.6-7.2)$ \\
\hline
\end{tabular}

Table 5. Comparison of mortality by causes between HIV-infected subjects and the general population of the

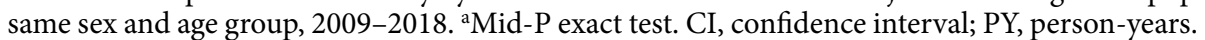


epidemiological change described in Spain ${ }^{27}$. Median age and time since the diagnosis of HIV increased due to the aging of the cohort. The percentage of patients who had been diagnosed with AIDS-defining events decreased throughout the study, due to the lower incorporation of new cases and the higher mortality associated with this situation $^{18-21,23,28,29}$. Although the proportion of people born out of Spain increased, they did not show higher mortality than Spain-born people as it has been reported in other countries ${ }^{26}$. This can be due to the less time of HIV-infection and the similar access to the HIV-diagnosis and treatment.

The average percentage of patients who had started antiretroviral therapy increased up to $87.9 \%$ in the 20142018 period, when the indication of this therapy was extended to all HIV diagnosed patients. Patients who had not started therapy may be explained by the transition process from old to new guidelines, patients deceased before starting of clinical follow-up, those who refuse treatments or who do not contact the healthcare system. This study was conducted in a country with universal and free of charge health-care coverage for the entire resident population, including HIV diagnosis and antiretroviral treatment. This fact discards socioeconomic reasons for not receiving medical follow-up and antiretroviral treatment; and therefore, differences in mortality should be explained by other causes. In Spain, it has been estimated that $29 \%$ and $48 \%$ of HIV diagnoses were done in patients with advanced disease and late diagnosis, respectively ${ }^{30}$. These figures show a potential for improvement according the 2020 UNAIDS strategy, which goals are $90 \%$ of HIV-infected people diagnosed, $90 \%$ of them receiving antiretrovirals, and $90 \%$ of those in treatment achieving viral suppression ${ }^{31}$.

The present work has some limitations. This descriptive population-based study is not adequate to evaluate survival or to conclude about causal factors since many participants did not enter at the seroconversion or HIV diagnosis, and variables such as antiretroviral therapy, viral load, CD4 cell count, smoking status and drug consumption were not monitored during the follow-up. The study has been carried out in a single region and the study size could be small for some analyses. The analysis was limited to the population with stable residence, and non-resident patients were not included. It has been described that populations with high mobility could have worse follow-up of their health problems ${ }^{32}$. Losses of follow-up are a relevant source of bias in cohort studies; however, people were included only during the period with residence and healthcare coverage in Navarra and a variety of information sources were used that virtually rules out losses of follow-up ${ }^{33}$. HIV-related mortality includes more causes than AIDS-mortality, therefore, care should be paid in comparison with studies that analysed AIDS mortality ${ }^{29,34}$. Since important sociodemographic changes happened in the study population, time-trend analyses were adjusted not only by sex and age, but also by country of birth and transmission category to maintain the comparability over time. The impact of direct-acting antiviral therapy of HCV infection in mortality could not be detected since this therapy was just being introduced in the last study period.

Only the main cause of death was considered, but not other relevant causes that could also contribute. These results are conditioned by the HIV epidemiology in Spain, where most HIV infections were acquired by risk practices related with injecting drug use. Undiagnosed HIV infections and mortality that could occur before diagnosis were not represented in this study.

\section{Conclusions}

Advances in the antiretroviral therapy and improvements in the management of HIV-infected patients have coincided with a progressive decline in HIV-related mortality in a population-based cohort of HIV-infected persons, mainly among those who had had diagnosis of AIDS-defined events, while non-HIV-related mortality remained stable. Despite the wide availability of antiretroviral therapies in Spain, HIV infection was still associated to important excess mortality, overall and by many specific non-HIV-related causes. These causes of death have surpassed HIV-related causes, and this trend probably will increase due to the progressive aging of the HIV infected population. Since antiretroviral therapy does not seem enough to correct the excess mortality, prevention of HIV infections in the population and promotion of healthy life styles in HIV-infected people must be a priority.

\section{Methods}

Design and population. This study analysed the population-based dynamic cohort of adults between 25 and 74 years old diagnosed with HIV infection and residing in Navarra, a northern Spanish region of 650,000 inhabitants approximately. The resident population in the region had easy and free access to medical care and to the HIV test in primary healthcare, specialized outpatient consultations and hospitals. Combined antiretroviral therapies have been available free of charge for the patient in $3 \mathrm{HIV}$-centres during the study period. HCV antiviral treatments have been offered to HCV co-infected patients and since 2014 direct-acting antiviral therapies were progressively offered to all co-infected patients.

Information sources and variables. HIV infection reporting is mandatory for healthcare professionals according to the Navarra Decree 383/1997, and patient consent is not required. This study analysed data from the enhanced epidemiological surveillance of HIV-infection that includes all cases confirmed in laboratories of the region since the beginning of the epidemic ${ }^{35}$. It has been prospectively updated by an automatic reporting of all new laboratory-confirmed cases and by the active search of HIV-infected patients attended in medical centres. AIDS-defining events were obtained from the AIDS case reporting system and the hospital discharge database, vital status was updated according the regional mortality register, and changes in the residence were updated from administrative databases of the Navarra Health Service ${ }^{35}$.

The variables considered were sex, birth date, transmission category (history of injecting drug use, men who had sex with men, heterosexual risk exposure, and other risk or unknown), country of birth (Spain or other), date of HIV diagnosis, hepatitis C antibody positive result, date of AIDS diagnosis, date of death and cause of death.

The reference general population consisted of persons residing in Navarra according to the census at the beginning of each year. From the regional mortality register we obtained the date and the underlying cause of 
death according to the International Classification of Diseases 10th edition ${ }^{36}$, for HIV-infected persons and for the general population. The causes of death were grouped into two main categories, HIV-related deaths (codes B20-B24 and R75) and non-HIV related deaths (all other codes). In the second category we considered separately: non-AIDS defining cancer (codes C00-D48), cardiovascular disease (codes I00-I99), respiratory disease (codes J00-J99), liver disease (codes B15-B19, B70, K73, K74, K769), drug addiction or overdose (codes F11, F16, F18, F19, X41, X42, X44, X45), suicide (codes X60-X84), other external causes (codes V01-Y89, when they were not included in the previous sections), and all other causes.

All data were treated in a strictly confidential manner according to the ethical principles of the Helsinki Declaration of 1964 revised by the World Medical Organization in Fortaleza 2013, and the Spanish and European personal data protection regulations. The study protocol was approved by the Navarra Public Health Authority and the Navarra Ethical Committee for Clinical Research. Patient information was anonymized prior to analysis.

Statistical analysis. The study period started on first January 1999 for previously diagnosed infections, on the date when HIV infection was diagnosed for new detected cases, and on the date of registration in the Navarra Health Service for previously diagnosed HIV-infected patients who came to reside in the region. The follow-up ceased at the date of death, the date of deregistration as a resident or by 31 December 2018, whichever came first.

Percentages were calculated for categorical variables and were compared by $\chi^{2}$ test. Median and interquartile range were obtained for quantitative variables which were compared by the Kruskall Wallis test.

The number of person-years of follow-up was used as the denominator for the calculation of average annual mortality rates for five-year periods. Poisson regression models were used to estimate average annual change in mortality rates, overall, by sex, age, history of injecting drug use, country of birth, diagnosis of an AIDS-defining event, HIV diagnoses before 1997 (year of extended use combined antiretroviral therapy) and groups of causes of death. Rate ratios of annual trend unadjusted and adjusted by sex, age-group (25-44, 45-54 and 55-74 years), transmission category and country of birth were calculated.

The number of observed deaths in the cohort of persons diagnosed with HIV infection was compared with expected mortality of the Navarra general population of the same sex and ten-year group of age. Relative excess mortality was estimated by standardized mortality ratios with their $95 \%$ confidence intervals obtained by the exact Mid-P method. Excess mortality rates were calculated as the difference of observed minus expected deaths and divided by the number of PY of follow-up. These analyses were repeated for each five-year period, sex, age group, transmission category and HIV diagnoses before or in or after 1997.

For the last ten-year period (2009-2018) observed mortality in the cohort of HIV-infected persons by causes was compared with the expected mortality estimated from the general population.

Received: 30 September 2019; Accepted: 11 May 2020;

Published online: 02 June 2020

\section{References}

1. Mocroft, A. et al. Decline in the AIDS and death rates in the EuroSIDA study: an observational study. Lancet 362, 22-29, https://doi. org/10.1016/s0140-6736(03)13802-0 (2003).

2. CASCADE Collaboration. Determinants of survival following HIV-1 seroconversion after the introduction of HAART. Lancet 362, 1267-1274, https://doi.org/10.1016/s0140-6736(03)14570-9 (2003).

3. May, M. T. et al. Impact on life expectancy of HIV-1 positive individuals of CD4+ cell count and viral load response to antiretroviral therapy. AIDS 28, 1193-1202, https://doi.org/10.1097/QAD.0000000000000243 (2014).

4. Samji, H. et al. Closing the gap: increases in life expectancy among treated HIV-positive individuals in the United States and Canada. Plos One 8, e81355, https://doi.org/10.1371/journal.pone.0081355 (2013).

5. Belvedere, L. M., Miller, C. L. \& Hogg, R. S. Shifting sands: changing regional and gender-specific patterns of HIV/AIDS mortality in Canada, 1987 to 2008. Can J Public Health 103, 202-206 (2012).

6. Kitahata, M. M. et al. Effect of early versus deferred antiretroviral therapy for HIV on survival. N Engl J Med 360, 1815-1826, https:// doi.org/10.1056/NEJMoa0807252 (2009).

7. Backus, L. I., Boothroyd, D. \& Deyton, L. R. HIV, hepatitis C and HIV/hepatitis C virus co-infection in vulnerable populations. AIDS 19(Suppl 3), S13-19, https://doi.org/10.1097/01.aids.0000192065.09281.01 (2005).

8. Helleberg, M. et al. Mortality attributable to smoking among HIV-1-infected individuals: a nationwide, population-based cohort study. Clin Infect Dis 56, 727-734, https://doi.org/10.1093/cid/cis933 (2013).

9. Smith, C. J. et al. Trends in underlying causes of death in people with HIV from 1999 to 2011 (D:A:D): a multicohort collaboration. Lancet 384, 241-248, https://doi.org/10.1016/S0140-6736(14)60604-8 (2014).

10. Aldaz, P. et al. Trends in mortality and causes of death among persons with HIV infection, 1985-2004 (in Spanish). Enferm Infecc Microbiol Clin 25, 5-10, https://doi.org/10.1157/13096746 (2007).

11. Collaboration of Observational HIV Epidemiological Research Europe (COHERE) in EuroCoord. et al. All-cause mortality in treated HIV-infected adults with CD $4 \geq 500 / \mathrm{mm}^{3}$ compared with the general population: evidence from a large European observational cohort collaboration. Int J Epidemiol 41, 433-445, https://doi.org/10.1093/ije/dyr164 (2012).

12. Gurm, J. et al. Suicide mortality among people accessing highly active antiretroviral therapy for HIV/AIDS in British Columbia: a retrospective analysis. CMAJ Open 3, E140-148, https://doi.org/10.9778/cmajo.20140101 (2015).

13. Aldaz, P. et al. Mortality by causes in HIV-infected adults: comparison with the general population. BMC Public Health 11, 300, https://doi.org/10.1186/1471-2458-11-300 (2011).

14. Insight Start Study Group, Lundgren, J. D. et al. Initiation of antiretroviral therapy in early asymptomatic HIV infection. $N$ Engl $J$ Med 373, 795-807, https://doi.org/10.1056/NEJMoa1506816 (2015).

15. Temprano ANRS 12136 Study Group, Danel, C. et al. A trial of early antiretrovirals and isoniazid preventive therapy in Africa. $N$ Engl J Med 373, 808-822, https://doi.org/10.1056/NEJMoa1507198 (2015).

16. Panel de expertos de GeSIDA y Plan Nacional sobre el Sida. GESIDA/National AIDS Plan: Consensus document on antiretroviral therapy in adults infected by the human immunodeficiency virus (Updated January 2015) (in Spanish). Enferm Infecc Microbiol Clin 33(8), 543.e1-43, https://doi.org/10.1016/j.eimc.2015.03.016 (2015).

17. Juanbeltz, R. et al. Progress in the elimination of hepatitis C virus infection: A population-based cohort study in Spain. Plos One 13, e0208554, https://doi.org/10.1371/journal.pone.0208554 (2018). 
18. Croxford, S. et al. Mortality and causes of death in people diagnosed with HIV in the era of highly active antiretroviral therapy compared with the general population: an analysis of a national observational cohort. Lancet Public Health 2, e35-e46, https://doi. org/10.1016/S2468-2667(16)30020-2 (2017).

19. Hernando, V. et al. All-cause mortality in the cohorts of the Spanish AIDS Research Network (RIS) compared with the general population: 1997-2010. BMC Infect Dis 13,382, https://doi.org/10.1186/1471-2334-13-382 (2013).

20. Eyawo, O. et al. Changes in mortality rates and causes of death in a population-based cohort of persons living with and without HIV from 1996 to 2012. BMC Infect Dis 17, 174, https://doi.org/10.1186/s12879-017-2254-7 (2017).

21. Pettit, A.C., et al. Increased non-AIDS mortality among persons with AIDS-defining events after antiretroviral therapy initiation. J Int AIDS Soc 21(1), https://doi.org/10.1002/jia2.25031 (2018).

22. Guaraldi, G. et al. Premature age-related comorbidities among HIV-infected persons compared with the general population. Clin Infect Dis 53, 1120-1126, https://doi.org/10.1093/cid/cir627 (2011).

23. Garriga, C. et al. Mortality, causes of death and associated factors relate to a large HIV population-based cohort. PLoS One 10, e0145701, https://doi.org/10.1371/journal.pone.0145701 (2015).

24. Trickey, A. et al. Cause-specific mortality in HIV-positive patients who survived ten years after starting antiretroviral therapy. PLoS One 11, e0160460, https://doi.org/10.1371/journal.pone.0160460 (2016).

25. Kowalska, J. D. et al. Promoting high standards of care for women living with HIV: position statement from the Women Against Viruses in Europe Working Group. HIV Med 19, 167-173, https://doi.org/10.1111/hiv.12565 (2018).

26. Burchell, A. N. et al. Cause-specific mortality among HIV-infected people in Ontario, 1995-2014: a population-based retrospective cohort study. CMAJ Open 7(1), E1-E7, https://doi.org/10.9778/cmajo.20180159 (2019).

27. Vigilancia Epidemiológica del VIH y sida en España 2017: Sistema de Información sobre Nuevos Diagnósticos de VIH y Registro Nacional de Casos de Sida. Madrid: Plan Nacional sobre el Sida - Instituto de Salud Carlos III, https://www.mscbs.gob.es/ ciudadanos/enfLesiones/enfTransmisibles/sida/vigilancia/doc/InformeVIH_SIDA_2018_21112018.pdf (2018).

28. Alejos, B. et al. Overall and cause-specific excess mortality in HIV-positive persons compared with the general population: Role of HCV coinfection. Medicine (Baltimore) 95, e4727, https://doi.org/10.1097/MD.0000000000004727 (2016).

29. Cheung, C. C. et al. Reductions in all-cause and cause-specific mortality among HIV-infected individuals receiving antiretroviral therapy in British Columbia, Canada: 2001-2012. HIV Med 17, 694-701, https://doi.org/10.1111/hiv.12379 (2016).

30. Oliva, J. et al. Predictors of advanced disease and late presentation in new HIV diagnosis reported to the surveillance system in Spain. Gac Sanit 28, 116-122, https://doi.org/10.1016/j.gaceta.2013.06.009 (2014).

31. UNAIDS. 2016-2021 Strategy. On the fast-track to the end AIDS. Geneva: UNAIDS, http://www.unaids.org/en/resources/ documents/2015/UNAIDS_PCB37_15-18 (2015).

32. Deblonde, J. et al. Restricted access to antiretroviral treatment for undocumented migrants: a bottle neck to control the HIV epidemic in the EU/EEA. BMC Public Health 15, 1228, https://doi.org/10.1186/s12889-015-2571-y (2015).

33. Buskin, S. E., Kent, J. B., Dombrowski, J. C. \& Golden, M. R. Migration distorts surveillance estimates of engagement in care: results of public health investigations of persons who appear to be out of HIV care. Sex Transm Dis 41, 35-40, https://doi.org/10.1097/ OLQ.0000000000000072 (2014).

34. Lima, V. D. et al. AIDS incidence and AIDS-related mortality in British Columbia, Canada, between 1981 and 2013: a retrospective study. Lancet HIV 2, e92-97, https://doi.org/10.1016/S2352-3018(15)00017-X (2015).

35. Caro-Murillo, A. et al. Evaluation of the surveillance system for human immunodeficiency virus infections of Navarra, Spain, 19852003 (in Spanish). Rev Esp Salud Publica 81, 387-389, https://www.mscbs.gob.es/biblioPublic/publicaciones/recursos_propios/resp/ revista_cdrom/vol81/Vol81_4/RS814C_387.pdf (2007).

36. World Health Organization: International statistical classification of diseases and related health problems: ICD-10. Second Edition. Geneva, Switzerland: World Health Organization, https://apps.who.int/iris/handle/10665/42980 (2004).

\section{Acknowledgements}

Financial support: This work has been funded by the EIPT-VHC project, which was supported by the Spanish Ministry of Health, and by the Carlos III Institute of Health with the European Regional Development Fund (INT17/00066 and INT19/00028).

\section{Author contributions}

Study conception and design: C.F., R.S.M. and J.C. Acquisition of data: C.F., A.A., C.M.I., J.R., M.R., M.G., Y.F. and J.C. Data analysis and interpretation: C.F., C.M.I., R.S.M. and J.C. Drafting of manuscript: C.F., C.M.I., R.S.M. and J.C. Revising manuscript for important intellectual content: C.F., A.A., C.M.I., J.R., M.R., M.G., Y.F., U.F., R.S.M., C.E. and J.C. All authors have read and approved the final manuscript. J.C. is the guarantor.

\section{Competing interests}

The authors declare no competing interests.

\section{Additional information}

Correspondence and requests for materials should be addressed to J.C.

Reprints and permissions information is available at www.nature.com/reprints.

Publisher's note Springer Nature remains neutral with regard to jurisdictional claims in published maps and institutional affiliations.

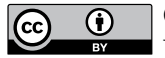

Open Access This article is licensed under a Creative Commons Attribution 4.0 International License, which permits use, sharing, adaptation, distribution and reproduction in any medium or format, as long as you give appropriate credit to the original author(s) and the source, provide a link to the Creative Commons license, and indicate if changes were made. The images or other third party material in this article are included in the article's Creative Commons license, unless indicated otherwise in a credit line to the material. If material is not included in the article's Creative Commons license and your intended use is not permitted by statutory regulation or exceeds the permitted use, you will need to obtain permission directly from the copyright holder. To view a copy of this license, visit http://creativecommons.org/licenses/by/4.0/.

(C) The Author(s) 2020 